for a short distance. A small round area of greyish colour lay to the outer side of the object, and at a distance of about $3 \mathrm{~mm}$. from the latter.

The eye was well cocainized, and an attempt was made to dislodge the foreign body by means of a blunt spud. It was of minute size, and somewhat mobile, but did not come away at first in front of the spud. After a little manipulation, however, I was able to dislodge it, and draw it downwards along the margin of the sclerotic, when I found, to my surprise, that it drew after it a small hair which had been imbedded in the subconjunctival tissue. 'The object first observed was obviously the root, which had become slightly bulbous, and opaque from inflammatory changes. The buried end of the hair was white and soft, and had lain apparently close to the greyish region already mentioned.

The eyeball had evidently been forcibly struck by a piece of grit which pierced the conjunctiva at the sclero-corneal margin, and passing in an outward direction carried with it an eyelash, the root of which remained above the surface at the limbus, setting up. a slight local irritation.

The fundus was normal, and no further treatment was necessary.

\title{
ANNOTATIONS
}

\section{A Prize in Ophthalmology}

THERE can be no greater stimulus to original work than the offering of prizes in special subjects. An excellent example is afforded in this country by the Middlemore Prize awarded triennially by the British Medical Association. Many of the essays written in competition for that prize remain as standard works upon ophthalmological subjects. We have reason, therefore, to be grateful to Mr. W. Edmonds and Miss S. Edmonds, of Wiscombe Park, Colyton, who havefounded a prize in ophthalmology in memory of their brother, Nicholas Gifford Edmonds, Lieutenant, 2nd Black Watch, who fell at Magersfontein, on December 11, 1899. The sum of $£ 100$ will be awarded every second year for the best essay (which must show evidence of original work) dealing with an ophthalmological theme, and the competition is open to all British subjects holding a medical qualification.

Subject to certain legal regulations, the management of the Gifford Edmonds Prize is vested in the hands of a Committee biennially nominated by the Medical Board of the Royal London Ophthalmic Hospital, who will select the subject of the essay and elect two 
examiners. The winner of the prize will be at liberty to give a lecture on the subject at the Royal London Ophthalmic Hospital.

It may be confidently anticipated that the new prize will furnish a strong stimulus to original work in ophthalmology, and $\mathrm{Mr}$. and Miss Edmonds may rest assured that their wish in founding the prize, that suffering may be alleviated, will be amply justified.

\section{The Need of Ophthalmic Laboratories and Museums}

It is fully recognized in general medicine and surgery that the only satisfactory method of teaching is attained when there is a thorough correlation of the pathological with the clinical aspects of disease.

The keen surgeon or physician will always substantiate or correct his diagnosis, when the opportunity offers, by careful post-mortem examination; and the clinical teacher stimulates his students most who exhibits specimens and microscopic slides to his class in order to show the exact changes in the organs and tissues which have given rise to the signs and symptoms.

For such teaching a well stocked and well arranged museum, together with a good series of typical microscopic sections or microphotographs, is essential. Successful ophthalmic teaching needs a similar equipment in order to make the diagnosis, prognosis, and treatment comprehensible.

How bewildering it is to students, nay, often to general practitioners, to understand why, in certain cases of glaucoma, eserin is curative and atropin is fatal, while in others the exact converse holds. Yet the mystery is dissipated, directly the anatomy of glaucoma is understood. Again, how difficult it is to comprehend the differential diagnosis between the various forms of pseudo-glioma till one understands their pathology. Or why glioma should appear at one time as a detached retina with a white background, and at others as nodding white masses in the vitreous, till one recognises the two forms of glioma exophytum and glioma endophytum. Examples could be indefinitely multiplied.

While in the throes of reorganization let us see to it that means are provided for students to be taught their pathology-both macroscopic and microscopic-that in our clinical instructions the pathological counterparts are adequately correlated. We cannot do this without ophthalmic laboratories and ophthalmic museums.

Many of our ophthalmic museums are incomplete and are often in a neglected state; too often we see the glycerine jelly melted in which the eyes have been mounted, and the valuable specimens degenerating. There is not sufficient accommodation for the display 